\title{
Analysis of Energy Expenditure during Walking using the Oxygen Consumption Method based on the Arch Type of the Students at the Sports Science Faculty of Universitas Negeri Jakarta
}

\author{
Wahyuningsih Djaali ${ }^{1}$, Sasanthy Kusumaningtyas ${ }^{2}$, Ermita Ibrahim ${ }^{3}$, Abdul Sukur ${ }^{4}$, Bazzar \\ Ari Mighra ${ }^{5}$ \\ \{inchy86@yahoo.com ${ }^{1}$, sasanthy@yahoo.com², ermitailyas@gmail.com ${ }^{3,}$ abdulsukur69@yahoo.com4, \\ bazzar.mighra@gmail.com ${ }^{5}$ \}
}

\begin{abstract}
Universitas Negeri Jakarta, Jl. Rawamangun Muka Jakarta Timur, Jakarta, Indonesia, ${ }^{1}$ Anatomy Department of Medical Faculty, Universitas Indonesia, Jakarta, Indonesia ${ }^{2}$ Physiology Department of Medical Faculty, Universitas Indonesia, Jakarta, Indonesia $3,4,5$
\end{abstract}

\begin{abstract}
Most of the studies examining the foot classified the foot arch into three types based on the index value by normal, low, and high. The varied foot arch structure caused an abnormal form of alignment require the foot to gain greater effort in performing its functions. This study aims to see the difference in energy expenditure during walking on three-foot arch types calculated by measuring oxygen consumption. The 24 students at the Faculty of Sports Science, Universitas Negeri Jakarta were divided equally into three groups of foot arch type. The selected foot arch type was based on the footprint ratio index. Each student walked without footwear for 6 minutes on a treadmill connected with a breath-by-breath automated gas-analysis system (FitMate Pro, Cosmed, Italy), while the oxygen consumption was calculated. The walking speed used was the most comfortable walking speed chosen by the students. The results showed that the lowarched type had the highest tendency of body weight, height, and body mass index, compared to the other two-foot arch types. Data analysis of oxygen consumption during walking on all three-foot arch types showed a significant difference $(\mathrm{p}=0.000)$. The smallest oxygen consumption is in the normal-arched type while the high-arched type, and the greatest is in the low-arched type. The foot arch type affects energy consumption during walking. The least energy consumption during walking is in normal-arched type, and the greatest one is in low-arched type.
\end{abstract}

Keywords: Foot Arch Type, Energy Expenditure, Walking, Oxygen Consumption.

\section{Introduction}

Most of the studies examining the foot classified the foot arch by using index reference values into three types: high-arched foot, normal foot, and low-arched foot or flat foot [1], [2]. Flat foot or pes planus is a condition that is quite common in adults. The prevalence of flat foot at the age of 18 to 25 years is $11.25 \%$ [3]. Flat foot is said to be related to hypermobility due to its hyperpronated structure [4]. Flat foot is also said to be more unstable in standing compared to the normal foot due to misalignment of the foot, and the use of footwear soles helps to align the shape of the foot thus improving the stability of the foot [5]. In the flat foot, 
the overly stretched fascia plantaris causes the intrinsic muscles of the footwork more heavily in compensating for the lack of stress, resulting in prolonged fatigue. The study of Fan et al., suggests that during walking, a person with a flat foot will feel tired faster than a person with a high-arched foot, due to the muscle tension that occurs [2]. The high-arched foot, or so-called pes cavus, is said to be relatively common, one of the studies mentioned that.

The incidence ranges from 14.6 to $25.8 \%$ [6]. The foot arch in this type of foot is said to be inflexible [4], making it less capable of being an effective shock-absorber during walking.

The differences in these foot arch types indicate that the structure of the foot affects the overall functioning of the lower extremity. In contrast to flat foot, in the high-arched foot has not found a study that examines energy expenditure in walking activities.

The energy expenditure during physical activity such as walking, running, and climbing, depends on several factors, such as the intensity of activity, the speed and distance traveled. The main and fundamental physiological parameters in estimating energy expenditure during activity are oxygen consumption [7], [8]. Therefore the amount of energy expenditure can be quantified by measuring oxygen consumption.

This study aims to see the difference in energy expenditure during walking on the three types of the foot arch, which is calculated by measuring oxygen consumption.

\section{Method}

\subsection{Participants}

This study was conducted in Senior High School 4 Kendari with the consideration that this school is a school with friendly environmental as evidenced by the title of Adiwiyata School since 2013. This study used a qualitative approach [9]. The types of data in this study were classified into primary data and secondary data. The methods of data collection in this study using observation, interview, and documentation. The data collection used purposive sampling system consisting of the principal, teacher of Religious Education, Chairman of Adiwiyata, Teacher of Craft, and some students of Senior High School 4 Kendari. The technical analysis of the data conducted in three ways: data reduction, data presentation, and conclusion. The testing of the validity of the research data had done by the researcher with conducted the extension of observation, increased persistence, and triangulation, either triangulation of time or engineering [10].

This research is observational analytic research with cross-sectional design. The study was conducted at Somatokinetics Laboratory of Faculty of Sport Science, Universitas Negeri Jakarta (FIO UNJ), from November 2016 to Avril 2017, and the study population was FIO UNJ students. Calculation of sample size is done by using a two-sided test formula. Using the $\mu$ values obtained from a study conducted by Otman et al, [11] the sample size was 24 people divided into three groups of foot arch (normal, low and high), each of eight people. All subjects had been given informed consent.

The inclusion criteria of research subjects are willing to complete informed consent form, aged between 18 to 25 years old, male sex, have IMT value 18,5 to $22,9 \mathrm{~kg} / \mathrm{m}^{2}$, have minimum $\mathrm{VO}_{2}$ max value in 'good' category (used Harvard Step Test method), have normal ECG results, no neuromusculoskeletal, cardiovascular and respiratory abnormalities that potentially affect the energy expenditure during walking, no history of injury or history of surgery in the lower 
limb in last three months, and individuals is in good health. While the exclusion criteria are absent, refused to be examined and uncooperative.

\subsection{Protocols}

The foot arch type is grouped based on the foot arch index value on footprint by using the footprint ratio index which was calculated with formula $=\mathrm{ab} / \mathrm{ac}$ (Figure 1). Index $\leq 0.258=$ low-arched foot, index $0.259-0.785=$ normal foot, and index $\geq 0.786=$ high-arched foot.[2]

The selection of research subjects was done through footprint examination using ink. Subjects stepped on millimeter block paper in a weight-bearing standing position to determine the foot arch type. Furthermore, each subject appropriating the inclusion criteria underwent two examination sessions.

In the first session, the most comfortable running speed was determined. Each subject walked on a treadmill beginning at a speed of $0.67 \mathrm{~m} / \mathrm{s}$, then gradually upgraded to $0.89 \mathrm{~m} / \mathrm{s}$, $1.11 \mathrm{~m} / \mathrm{s}, 1.33 \mathrm{~m} / \mathrm{s}$, and $1.56 \mathrm{~m} / \mathrm{s}$. Each speed was maintained for one minute and then upgraded until the subject chose the most comfortable speed. The same procedure was repeated from the highest speed $(1.56 \mathrm{~m} / \mathrm{s})$. The final velocity was the average of both speeds chosen.

In the second session, each subject was asked to come by previously, not consuming cigarettes, coffee and tea, and not eating heavy meals for at least two hours before the examination began. Each subject was required to walk on a treadmill without using footwear for six minutes at the chosen walking speed. The treadmill was connected with a breath-bybreath automated gas-analysis system (FitMate Pro, Cosmed, Italy) that monitors the oxygen uptake $\left(\mathrm{VO}_{2}\right)$ and heart rate (HR) during the walking activity. The oxygen consumption $\left(\mathrm{O}_{2}\right.$ cost) was calculated with formula $=\mathrm{VO}_{2} /$ walking speed. This value described the energy expenditure during walking.

\subsection{Statistical Analysis}

The statistic procedure was performed using SPSS 20 program. Normality and homogeneity of variances were performed as a prerequisite analysis test. ANOVA one way tests were performed on outcome variables to determine if there were significant differences due to foot arch type: $P<0.05$ defined significance. If significant main effects were observed, then used the Bonferroni method to perform post hoc pairwise multiple comparisons.

\section{Results}

This study describes the foot arch type data which is associated with age (year), weight (kilogram), height (centimeter) and body mass index $\left(\mathrm{kg} / \mathrm{m}^{2}\right)$ to show the profile of the research subjects (Table 1). It appears that in the low-arched foot type has the highest tendency of body weight, height and body mass index, compared with the other two-foot arch types. 
Table 1. Description of foot arch type associated with age, weight, height, and body mass index (BMI)

\begin{tabular}{lcccc}
\hline \multicolumn{1}{c}{ Variables } & $\begin{array}{c}\text { Subject Total } \\
(\mathbf{n = 2 4})\end{array}$ & $\begin{array}{c}\text { Normal Foot } \\
(\mathbf{n = 8})\end{array}$ & $\begin{array}{c}\text { Low-arched Foot } \\
(\mathbf{n = 8})\end{array}$ & $\begin{array}{c}\text { High-arched Foot } \\
(\mathbf{n = 8})\end{array}$ \\
\hline Age $(\bar{x} \pm$ SD) year & $18,25 \pm 0,44$ & $18,25 \pm 0,46$ & $18,25 \pm 0,46$ & $18,25 \pm 0,46$ \\
Weight $(\bar{x} \pm$ SD) kg & $57,96 \pm 6,64$ & $56,56 \pm 7,23$ & $61,06 \pm 6,06$ & $56,25 \pm 6,25$ \\
Height $(\bar{x} \pm$ SD) $\mathrm{cm}$ & $168,04 \pm 6,25$ & $167,50 \pm 7,09$ & $169,25 \pm 5,39$ & $167,38 \pm 6,80$ \\
BMI $\left(\bar{x} \pm\right.$ SD) $\mathrm{kg} / \mathrm{m}^{2}$ & $20,48 \pm 1,49$ & $20,11 \pm 1,58$ & $21,29 \pm 1,41$ & $20,04 \pm 1,30$ \\
\hline
\end{tabular}

Foot arch index data in this study, which is calculated using the footprint ratio index, is measured on both feet (Table 2). The correlation between the footprint ratio index of right and left foot has a very strong correlation (Pearson correlation $=0.979)$.

Table 2. 'Footprint ratio index' on three types of foot arches

\begin{tabular}{lccccc}
\hline \multirow{2}{*}{$\begin{array}{c}\text { Foot arch } \\
\text { type }\end{array}$} & $\mathbf{n}$ & \multicolumn{3}{c}{ Footprint ratio index } \\
\cline { 3 - 6 } & & $\overline{\boldsymbol{x}} \pm$ SD & Range & $\overline{\boldsymbol{x}} \pm$ SD & Reft \\
\cline { 3 - 6 } & 8 & $0.54 \pm 0.03$ & $0.5-0.58$ & $0.53 \pm 0.05$ & $0.48-0.63$ \\
Normal & 8 & $0.16 \pm 0.06$ & $0.09-0.24$ & $0.17 \pm 0.06$ & $0.08-0.24$ \\
Low & 8 & $0.806 \pm 0.01$ & $0.79-0.83$ & $0.81 \pm 0.01$ & $0.79-0.83$ \\
High & &
\end{tabular}

Data of oxygen consumption in this study illustrates the energy expenditure during walking (Table 3$)$. The smallest oxygen consumption was in the normal foot type $(0.186 \pm$ $0.019 \mathrm{ml} / \mathrm{kg} / \mathrm{m})$, and the largest oxygen consumption was in the low-arched foot type $(0.269 \pm$ $0.036 \mathrm{ml} / \mathrm{kg} / \mathrm{m})$. Data analysis with one-way ANOVA test showed a significant difference among the three groups $(P=.000)$, and advanced statistical test with Post-Hoc Bonferroni are shown in Table 4.

Table 3. Description of oxygen consumption during 6-minute walking on three types of foot arches

\begin{tabular}{lcccc}
\hline \multirow{2}{*}{ Foot arch type } & $\mathbf{n}$ & \multicolumn{2}{c}{$\begin{array}{c}\text { Oxygen consumption } \\
(\mathbf{m l} / \mathbf{k g} / \mathbf{m})\end{array}$} & \multirow{2}{*}{$\boldsymbol{P}$ value } \\
\cline { 3 - 4 } & & $\overline{\boldsymbol{x}} \pm \mathbf{S D}$ & Range & \\
\hline Normal & 8 & $0.186 \pm 0.019$ & $0.15-0.20$ & \\
Low & 8 & $0.269 \pm 0.036$ & $0.21-0.34$ & 0.000 \\
High & 8 & $0.226 \pm 0.021$ & $0.20-0.25$ & \\
\hline
\end{tabular}

Table 4. Post-hoc analysis ( $P$ value) of oxygen consumption during 6-minute walking on three types of foot arches

\begin{tabular}{lccccc}
\hline Foot arch type & $\overline{\boldsymbol{x}} \pm \mathbf{S D}$ & $\begin{array}{c}\text { Between } \\
\text { groups }\end{array}$ & $\begin{array}{c}\text { Normal vs. } \\
\text { Low }\end{array}$ & $\begin{array}{c}\text { Normal vs. } \\
\text { High }\end{array}$ & $\begin{array}{c}\text { Low Vs. } \\
\text { High }\end{array}$ \\
\hline Normal & $0.186 \pm 0.019$ & & & & \\
Low & $0.269 \pm 0.036$ & 0.000 & 0.000 & 0.017 & 0.012 \\
High & $0.226 \pm 0.021$ & & & & \\
\hline
\end{tabular}




\section{Discussion}

Foot examination using the footprint method is easy, fast, more practical, and simpler than some other methods such as photography, somatometry, and radiographic evaluation [6]. This footprint method belongs to the indirect method of measuring ALM that can provide information about the foot arch type using some formula calculations, including footprint ratio index, Clark's angle (footprint angle), Chippaux-Simirak index, arch index, and SztriterGodunow index (Ky) [6], [10]. In this study, the footprint method is used with the calculation footprint ratio index formula to determine the arch type of the subject's foot.

This study describes the foot arch type associated with several variables, that is age, weight, height, and body mass index. The results show that the low-arched foot type has the highest tendency of body weight, height, and BMI compared to the other two-foot arch types. These results are by a study conducted by Wozniacki [6], who examined the relationship between the foot arch type with the degree of obesity. The result obtained is that there is a significant relationship between the foot arch type with the degree of obesity, especially in women. In contrast, a study conducted by Ahmad [11], who examined the prevalence of flat foot in children, revealed that body mass index was not associated with flat foot incidence.

The data of the foot arch index in this study was presented to show the profile of the foot arch index on the three types of foot arches taken as the subject of the study. The foot arch index is measured using the footprint ratio index formula [2], performed on both feet. In the grouping of the foot arch type based on this formula, all the research subjects had a foot arch index value, either on the right or the left foot, included within the range of the grouping of foot arch type. Therefore, a correlation test is performed between the footprint ratio index of the right foot and the left foot. The correlation test result shows a very strong correlation (Pearson correlation $=0.979)$.

This study aims to examine the energy expenditure during walking in the three-foot arch types. This is to determine whether the foot arch type affects the energy expenditure during walking. Oxygen consumption can represent the total energy required to perform a submaximal physical activity, such as walking. The most accurate method of measuring oxygen consumption is breath-by-breath analyzer [12], [13]. With the breath-by-breath analyzer, it can be monitored the oxygen uptake during physical activity. This study uses a breath-by-breath automated gas-analysis system (FitMate Pro, Cosmed, Italy).

The results obtained in this study were there was a significant difference $(P=.000)$ in oxygen consumption during walking on the three foot arch types. This suggests that the foot arch type affects the energy expenditure during walking, which is calculated by measuring the oxygen consumption. By the results of a study conducted by Fan et al. [2], results of this study show that the largest oxygen consumption during walking is in the low-arched foot type, followed by the high-arched foot type, and the smallest oxygen consumption is in the normal foot type. This may be due to the low-arched foot has lower stability and requires greater plantar muscle tension [2], and in this type of foot also occurs the loss of function of the medial longitudinal arcus [14].

The second greatest oxygen consumption during walking is high-arched foot type, which also has a significant difference, both with low-arched foot type $(P=.012)$ and with normal foot type $(P=.017)$. This may be due to the muscle imbalance occurring in the supination position of the high-arched foot [6], and as a result of the more supine foot position, this makes little pronation during the stance phase, both on standing and walking [15]. In these circumstances, the distribution of forces received from the body to the foot is not optimal as in the normal foot [16], which can then cause a person to require greater effort in walking. 


\section{Conclusion}

The foot arch type affects the energy expenditure during walking as measured by oxygen consumption. The least energy expenditure is in the normal foot type, and the greatest energy expenditure is in the low-arched foot type.

\section{References}

[1] Wong CK, Weil R, Boer Ed.: Standardizing foot-type classification using arch index values Physiotherapy Canada. Vol. 64, pp. 280-3 (2012)

[2] Fan Y, Fan Y, Li z, L, Donglin L.: Natural gaits of the non-pathological flat foot and high-arched foot PLoS one, Vol. 6. pp. Hal 1-5 (2011)

[3] Bhoir MT.: Prevalence of flat foot among 18-25 years old physiotherapy students: cross sectional study Indian Journal of Basic and Applied Medical Research. Vol. 3, pp. 272-8 (2014)

[4] Kaufman KR, Brodine SK, Shaffer RA, Johnson CW, Cullison TR..: The effect of foot structure and range of motion on musculoskeletal overuse injuries The American Journal of Sports Medicine. Vol. 27, pp. 585-93 (1999)

[5] Satvati B .: Standing stability evaluation in subjects with flat foot Journal of Research in Rehabilitation Sciences. Vol 8, pp. 1277-84 (2013)

[6] Woźniacka R .: Body weight and the medial longitudinal foot arch: high-arched foot, a hidden problem European journal of pediatrics. Vol. 172, pp. 683-9 (2013)

[7] Hagberg K.: Reproducibility of the physiological cost index among individuals with a lowerlimb amputation and healthy adults Physiotherapy Research International. Vol. 16, pp. 92-100 (2011)

[8] McArdle WD.: Exercise physiology: nutrition, energy, and human performance Lippincott Williams \& Wilkins. pp. 163-77 (2010)

[9] Mansoubi M.: Energy expenditure during common sitting and standing tasks: examining the 1.5 MET definition of sedentary behaviour BMC public health. Vol. 15, pp. 516 (2015)

[10] Brehm MA.: Age-related longitudinal changes in metabolic energy expenditure during walking in boys with Duchenne muscular dystrophy PloS one. Vol 9, pp. 1-3 (2014)

[11] Otman S .: Energy cost of walking with flat feet Prosthetics and orthotics international Vol. 12, pp. 73-6. (1988)

[12] Ahmad A.: Prevalence of flat foot among children in schools of University Town Peshawar, Pakistan Rawal Medical Journal. Vol. 41, pp. 465-6 (2016)

[13] Forriol F and Pascual J.: Footprint analysis between three and seventeen years of age Foot \& ankle. Vol. 11, pp. 101-4 (1990)

[14] Sivachandiran S and Kumar GV.: Effect of corrective exercises programme among athletes with flat feet on foot alignment factors Indian Journal of Orthopaedics. Vol. 2, pp. 119-23 (2016)

[15] Williams III DB.: Increased medial longitudinal arch mobility, lower extremity kinematics, and ground reaction forces in high-arched runners Journal of athletic training. Vol. 49, pp. 290-6 (2014)

[16] Hamill $\mathbf{J}$ and Knutzen KM.: Biomechanical basis of human movement Lippincott Williams \& Wilkins. Pp. 223-39 (2006) 